\title{
Challenges and Opportunities in Inclusion of Students with Physical Disabilities in Physical Education Practical Classes in North Shewa Zone, Ethiopia
}

\author{
Abiyot Kassaw, Tewodros Abir, Alemayehu Ejigu, Arefayene Mesfin \\ Sport Science Department, Collage of Natural and Computational Science, Debre Berhan University, Debre Birhan, Ethiopia \\ Email address: \\ abiyotk2004@gmail.com (A. Kassaw) \\ To cite this article: \\ Abiyot Kassaw, Tewodros Abir, Alemayehu Ejigu, Arefayene Mesfin. Challenges and Opportunities in Inclusion of Students with Physical \\ Disabilities in Physical Education Practical Classes in North Shewa Zone, Ethiopia. American Journal of Sports Science. \\ Vol. 5, No. 2, 2017, pp. 7-13. doi: 10.11648/j.ajss.20170502.11
}

Received: April 8, 2017; Accepted: May 9, 2017; Published: June 14, 2017

\begin{abstract}
The main focus of this study was to investigate the Challenges and Opportunities in Inclusion of Students with Physical Disabilities in Physical Education Practical Classes in the case of Secondary Schools of North Shewa Zone. Purposive sampling method has been employed to select 50 students, 9 PE teachers, 9 school principals, 9 Woreda and 2 zone educational experts, a total of 79 participants have been involved in this study. The sample population included students with orthopedic, visual and hearing impairments, physical education teachers, school principals, woreda, and zone education bureau experts. Descriptive survey research designs was employed for this study because it is believed that this types of research design is appropriate to cover large area of population and to assess the existing situation. Both qualitative and quantitative methods of data analysis were adopted. To collect the required information different data gathering instruments such as questionnaire, interview and field practical observation were used. The data gathered through questionnaire was handled by using statistics such as frequency, percentage, and mean whereas that of interview and practical field observation was described by using narrative approach. Findings of the study was Lack of teachers' support and encouragement for students with disabilities in PE practical classes; Inadequate training and poor experience of teachers of physical education; Lack of relevant curriculum materials like textbooks, teachers' guides etc. for SWD; Lack of professional support from Woreda and zone education bureau officers to schools in order to promote inclusive PE; Lack of support and consideration from school administration. Based on the findings and observation made the following recommendations were given; the school has to support and encourage teachers to produce and utilize relevant instructional materials which are locally made to promote the teaching-learning process in field activities; the government has to provide long-term and short-term trainings at regional and central level for teachers who are teaching in inclusive school; the ministry of education must prepare clearly stated guidelines to provide inclusive education to children with different types of disability.
\end{abstract}

Keywords: Opportunities, Hindering Factors, Disabilities, Outlooks, Challenges

\section{Introduction}

The problems of children with disabilities are so diverse and complex. They are facing various life challenges due to the complex socio-economic factors. All these factors have a profound implication on the effective functioning and adjustment of persons with disabilities. If the social environment is a rejecting, insensitive, hostile and degrading type, it will not only complicate the adjustment of these persons but also affects their development and self-esteem.
This is usually characterized by lack of trust and confidence in oneself and the surrounding, low self-esteem, and feeling of hopelessness (Tirusew, 2000).

It is the phase of general education that contributes to the mental, physical, psychological and social growth and development of the child primarily through selected movement experiences and physical activities (Dauer, and Pangrazi, 1979). 
As seen from the general trend, although most educators consider inclusive education to be sound for students with disabilities including those with orthopedic, visual and hearing impairments, a number of influencing factors interfered with its effective implementation. This is also true to successfully accommodate these students in PE practical activities. For instance, a study done by Degefa (2001) magnified the following problems to involve students with disabilities in PE practical classes: teachers often perceive only the difference or impairment of the students rather than students' ability, they show reluctance to include student with disabilities, they also found it difficult to evaluate these students in the practical session of PE, insufficiency of materials especially designed to meet the needs of students with disabilities and lack of relevant training of PE teachers. Hence, these and other factors could affect the significant participation of the subject students in PE practical activities. For the purpose of reaching on the sound inclusion of students with physical disabilities in PE practical classes, therefore, systematic assessment in the area becomes considerably essential. Thus, bearing this in mind, the purpose of this study is to explore the pedagogical challenges and opportunities in inclusion of students with physical disabilities in regular practical classes particularly in some selected secondary schools of North Shewa Zone of Amhara Regional Sate.

\section{Objective of the Study}

The overall objective of this study is to investigate the existing involvement of students with orthopedic, visual, and hearing impairments in PE regular practical classes and to identify opportunities provided and determinants in some selected secondary schools of North Shewa Zone.

In light with this, the study has the following specific objectives: to examine to what extent children with disabilities are involved in PE regular practical classes; to identify the major factors that hinder the involvement of students with physical disabilities in Physical Education practical class; to explore the awareness level of stakeholders (teachers, school principals, parents and others) about the inclusion of students with disabilities in PE practical classes; to explore the effort done by PE teachers, school principals and others to create effective inclusive PE practical classes in the school; and to suggest possible recommendations to improve the degree of involvements of these children in the PE practical session. To this end, the study tries to answer the following basic research questions.

1. Are students with disabilities being involved in Physical Education regular practical classes?

2. What are the major factors that hinder the involvement of students with physical disabilities in Physical Education practical activities?

3. What are the attitudes and awareness of stakeholders (teachers, school principals, parents and others) about the inclusion of students with disabilities in PE practical classes?
4. What strategies should be used to significantly accommodate students with physical disabilities in Physical Education regular practical classes?

This study would be designed in the direction to investigate challenges and opportunities in inclusion of students with physical disabilities in physical education practical classes in the case of secondary schools of north shewa zone. The researchers of this study hopes that the findings of the study would contribute to: Indicate the extent to which PE practical classes are open and conducive for children with disabilities in secondary schools, Initiate teachers, school principals and others to give chance and encourage these children to be concerned in PE practical programs in schools, Moreover, the findings will serve as a piece of reference to other researchers who are interested to undertake further study in the area and to contribute little in order to enrich the existing literature gap in the field.

\section{Research Methodology}

This research was conducted in some selected secondary schools of North Showa Zone (Chacha, Anchekorer, Mezezo, Arbegnoch, Shewa Robit, Aliyu Amba, Keyit, Enewari, Ataye secondary school)was selected as a school where to conduct this research due to its convenience in relation to time, money and work place for the researchers.

Descriptive survey research designs was employed for this study because it is believed that this types of research design is appropriate to cover large area of population and to assess the existing situation. The intention of this study was to collect empirical data on the existing involvement, challenges and opportunities of students with physical disabilities in PE regular practical classes. The research was conducted through in-depth analysis of the condition of students with orthopedic, visual and hearing impairments in secondary schools (grade 9-10) of North Shewa Zone of Amhara Regional State.

Currently there are about 35 secondary (grade 9-10) schools in North Shewa Zone of Amhara Regional State and the research were conducted in 9 randomly selected secondary schools which are $25.7 \%$ of the total school in this zone. The target population of the study was students who had experienced Orthopedic, Visual and Hearing impairments and attending their education in these regular schools in 2014/15 academic year. PE teachers, school principals, woreda and zone educational experts have been also included in the sample population. Thus, 50 students, 9 PE teachers, 9 school principals, 9 woreda and 2 zone educational experts were selected. Therefore, a total of 79 subjects have been involved in this study.

In order to select woredas and sample from the target population, the researchers adapted simple random and purposive sampling strategies. Simple random sampling method was employed as of selecting secondary schools while purposive sampling method has been employed to select the whole subjects of the study which were students with disabilities, PE teachers, school principals, woreda and 
zone educational experts.

In this study, both qualitative and quantitative analytical procedures were employed. Therefore, the data obtained through the sets of questionnaires was analyzed quantitatively. For quantitative analysis, frequency distribution, percentage and mean were employed. The data collected through interview and observations were analyzed qualitatively to substantiate the quantitative analysis.

Finally, the data were analyzed and discussed to reach certain finding which in turn was used to give conclusion and possible recommendations. In addition to this documents were used to triangulate the responses.

\section{Result and Discussions}

Table 1. A Prevalence and Sex in Sample Schools.

\begin{tabular}{llllll}
\hline \multirow{2}{*}{ No. } & \multirow{2}{*}{ School } & Sex & & \\
\cline { 3 - 6 } & & Male & Female & Total & \% \\
\hline 1 & Chacha & 1 & 0 & 1 & $2 \%$ \\
2 & Anchekorer & 2 & 1 & 3 & $6 \%$ \\
3 & Mezezo & 5 & 3 & 8 & $16 \%$ \\
4 & Ataye secondary school & 7 & 3 & 9 & $18 \%$ \\
5 & Shewa Robit & 5 & 5 & 10 & $20 \%$ \\
6 & Aliyu Amba & 1 & 0 & 1 & $2 \%$ \\
7 & Keyit & 3 & 2 & 5 & $10 \%$ \\
8 & Enewari & 5 & 1 & 6 & $12 \%$ \\
9 & Arbegnoch & 5 & 2 & 7 & $14 \%$ \\
Total & & 33 & 17 & 50 & 100 \\
\hline
\end{tabular}

Table 2.Disability Conditions of the students.

\begin{tabular}{|c|c|c|c|c|c|c|c|}
\hline No & Type of disability & Male & $\%$ & Female & $\%$ & Total & $\%$ \\
\hline 1 & Orthopedic & 24 & $48 \%$ & 10 & $20 \%$ & 34 & $68 \%$ \\
\hline 2 & Visual & 3 & $6 \%$ & 2 & $4 \%$ & 5 & $10 \%$ \\
\hline 3 & Hearing & 3 & $6 \%$ & 3 & $6 \%$ & 6 & $12 \%$ \\
\hline 4 & Orthopedic \& Hearing & 1 & $2 \%$ & 1 & $2 \%$ & 2 & $4 \%$ \\
\hline 5 & Orthopedic \& Visual & 2 & $4 \%$ & 1 & $2 \%$ & 3 & $6 \%$ \\
\hline
\end{tabular}

As indicated in Table 1, the prevalence of students with orthopedic, visual and hearing impairments in all 9 sample schools was 50 . Out of this figure33 (66\%) were males and $17(34 \%)$ were females. In terms of their distribution in each school, the highest number $10(20 \%)$ of these students were found in Shewa Robit secondary and preparatory school whereas the least number $1(2 \%)$ of them were found in Chacha and Aliyu Amba Secondary Schools.

One can observe from Table 2, that majority 34 (68\%) of these students were students with Orthopedic impairments whereas students with visual and hearing impairments have found $5(10 \%)$ and $6(12 \%)$ each respectively. On the other hand, $3(6 \%)$ and $2(4 \%)$ of the total students have multidisabilities which means orthopedic plus visual and orthopedic plus hearing impairments respectively. From this data it is possible to say that orthopedic impairment is the very common disability among the students in North Shewa Zone of Amhara Regional State.

Opportunities and Challenges of Inclusion in PE Practical

\section{Classes}

In the following part, the subjects asked to indicate their responses on a three point scale ranging from agree to disagree. Agree was given 5 points and disagree was given 1 point. The response undecided was given 3 points. The responses given by all the subjects was added and divided to the number of subjects to get the mean. The value of mean is 3 . The mean values are interpreted throughout the text as follows:

Table 3. Key.

\begin{tabular}{ll}
\hline DA & Disagree \\
UD & Undecided \\
$\mathrm{A}$ & Agree \\
$\Sigma$ & Summation \\
$\mathrm{M}$ & Mean \\
\hline & \\
\hline Mean & Interpretation \\
$3.5 \&$ above & Strong \\
$3.00-3.49$ & Moderate \\
$1.00-2.99$ & Low \\
\hline
\end{tabular}

Table 4. Views on Teachers' Competence.

\begin{tabular}{|c|c|c|c|c|c|c|c|}
\hline \multirow{3}{*}{ No } & \multirow{3}{*}{ Item } & \multicolumn{6}{|c|}{ Rating scales } \\
\hline & & & $\mathbf{A}$ & UD & DA & $\Gamma$ & $\mathbf{M}$ \\
\hline & & & 5 & 3 & 1 & 2 & $\mathbf{M}$ \\
\hline \multirow{2}{*}{3.} & \multirow{2}{*}{$\begin{array}{l}\text { Teachers support and encourage students with disabilities to participate in inclusive } \\
\text { (PE) practical classes }\end{array}$} & $f$ & 4 & - & 46 & 50 & \multirow{2}{*}{1.32} \\
\hline & & $\%$ & $8 \%$ & & $92 \%$ & 100 & \\
\hline \multirow{2}{*}{4.} & \multirow{2}{*}{$\begin{array}{l}\text { Teachers modify PE practical activities in order to meet the special needs of } \\
\text { students with disabilities }\end{array}$} & $f$ & 3 & - & 47 & 50 & \multirow{2}{*}{1.24} \\
\hline & & $\%$ & $6 \%$ & & $94 \%$ & 100 & \\
\hline \multirow{2}{*}{5.} & There is willingness of teachers to help students with disabilities personally in & $f$ & 3 & 1 & 46 & 50 & \multirow{2}{*}{1.28} \\
\hline & order to make them active participants of PE practical classes & $\%$ & $6 \%$ & $2 \%$ & $92 \%$ & 100 & \\
\hline \multirow{2}{*}{6.} & Teachers explain and demonstrate practical lessons of PE from simple to complex & $f$ & 4 & - & 46 & 50 & \multirow{2}{*}{1.32} \\
\hline & so that students with disabilities can catch up and imitate easily & $\%$ & $8 \%$ & & $92 \%$ & 100 & \\
\hline \multirow{2}{*}{7.} & Effort is made by teachers to encourage cooperation and friendship among disabled & $f$ & 7 & 2 & 41 & 50 & \multirow{2}{*}{1.36} \\
\hline & and non- disabled students in PE in order to help one another & $\%$ & $14 \%$ & $4 \%$ & $82 \%$ & 100 & \\
\hline \multirow{2}{*}{8.} & Students with disabilities have no possibility to ask and communicate with their & $f$ & 3 & - & 47 & 50 & \multirow{2}{*}{1.24} \\
\hline & teachers during practical session of PE & $\%$ & $6 \%$ & & $94 \%$ & 100 & \\
\hline
\end{tabular}


Concerning competency of teachers in table 3 , the majority $46(92 \%)$ of the respondents responded that teachers have never support and encourage them to be involved in PE practical activities. This indicates that teachers' competence in inclusive physical education is very low.

Regarding Teachers modification of PE practical activities in the table 3, the majority $47(94 \%)$ of the respondents replied that teachers did not try to modify PE activities by using different techniques in order to create conducive inclusive environment. According to, Salend (1994) advocated that a variety of techniques exist for adapting the learning environment to promote the optimal performance of main-streamed students, the selection of an appropriate modification will depend on several factors, including the students' learning needs and the teachers' instructional styles.

Concerning the willingness of teachers to help disabled students in table 3, most $46(92 \%)$ of the respondents replied that teachers do not show their willingness to support students with disability and helping them to be active participant.

Regarding the teachers methods of teaching practical class, majority $46(92 \%)$ of the respondents replied that PE teachers do not give much attention for explaining and demonstrating practical activities for students with different disabilities.

Concerning effort is made by PE teachers to encourage SWD most, $41(82 \%)$ of the respondents replied that

PE teachers do not show any effort and encouragement students with disabilities, whereas $7(14 \%)$ of the respondents replied that PE teachers encourage students with disabilities

Regarding possibility of SWD to communicate with their PE teachers, the majority $47(94 \%)$ of the respondents responded that SWD have no possibility to communicate with their PE teachers concerning their participation on practical sessions. According to Hundert (1982) cited in Salend (1994) advocated the need of communication in inclusive education as "successful main-streaming depends on an ongoing process of good communication and cooperation."

Table 5. Assessment Techniques used by PE teachers.

\begin{tabular}{|c|c|c|c|c|c|c|c|c|c|}
\hline \multirow{3}{*}{ No } & \multirow{3}{*}{ Item } & \multicolumn{8}{|c|}{ Rating scales } \\
\hline & & \multicolumn{2}{|l|}{$\mathbf{A}$} & \multicolumn{2}{|c|}{ UD } & \multicolumn{2}{|l|}{ DA } & \multicolumn{2}{|c|}{ Total } \\
\hline & & No & $\%$ & No & $\%$ & No & $\%$ & No & $\%$ \\
\hline 9. & $\begin{array}{l}\text { Evaluation mechanisms used by teachers consider disability of students in practical } \\
\text { classes of PE }\end{array}$ & 2 & $4 \%$ & 1 & $2 \%$ & 47 & $94 \%$ & 50 & $100 \%$ \\
\hline 10. & $\begin{array}{l}\text { Result of students with disabilities in PE is proportional with result of students with } \\
\text { non-disabilities }\end{array}$ & 4 & $8 \%$ & 1 & $2 \%$ & 45 & $90 \%$ & 50 & $100 \%$ \\
\hline 11. & Students with disabilities did not involve in the practical examinations of PE & 32 & $64 \%$ & 1 & $2 \%$ & 17 & $34 \%$ & 50 & $100 \%$ \\
\hline
\end{tabular}

As indicated in item 9 of Table 4, almost all 47 (94\%) of the students replied that the evaluation mechanisms used by PE teachers did not consider the special needs of SWD in PE. Regarding item 10 of Table 4, majority 45(87.23\%) of the respondent students indicated that their result in this subject is not proportional with that of the 'normal' students. Similarly, in item 11 of the same table $32(64 \%)$ of these students replied agree concerning their rejection from the practical tests.

Hence, from the above result one can observe that teachers in the sample schools did not use pertinent evaluation methods which consider the disabilities of these students and otherwise they totally excluded SWD from the practical tests. As a result of this SWD achieve poor results. However, isolation in the process of inclusion is contradictory and it might be the major reason for several psycho-social problems and poor achievement. With this regard, Auxter, Pyfer and Huetting (1997) advocated that, assessment is an inseparable part of the students' ongoing educational program, and it is particularly critical for students with disabilities. Hence, they underlined that the teacher in the inclusive classes should know the purposes of assessment and types of assessment match to the purposes.

Table 6. Support and Encouragement from Educational Officials.

\begin{tabular}{|c|c|c|c|c|c|c|c|}
\hline \multirow{3}{*}{ No } & \multirow{3}{*}{ Item } & \multicolumn{6}{|c|}{ Rating scales } \\
\hline & & & $\mathbf{A}$ & UD & DA & \multirow{2}{*}{$\sum$} & \multirow{2}{*}{$\mathbf{M}$} \\
\hline & & & 5 & 3 & 1 & & \\
\hline \multirow{2}{*}{14.} & Effort is made by school administrators to follow the participation and evaluation systems of & $f$ & 1 & 1 & 48 & 50 & \multirow{2}{*}{1.12} \\
\hline & students with disabilities in PE practical classes are satisfactory. & $\%$ & $2 \%$ & $2 \%$ & $96 \%$ & 100 & \\
\hline \multirow{2}{*}{15.} & Zone and woreda educational experts provide professional assistance for teachers to create & $f$ & 1 & - & 49 & 50 & \multirow{2}{*}{1.08} \\
\hline & effective inclusion in PE practical classes & $\%$ & $2 \%$ & & $98 \%$ & 100 & \\
\hline
\end{tabular}

Regarding the effort made by school administrators, in the above table, the majority $48(96 \%)$ of the respondents responded that school administrators are not show effort to check out the participation and evaluation systems of students with disabilities in PE practical classes. The mean value (1.12) of this item which is far from the average (3) also informed us that the negligible attention given for the special interest of the subjects in inclusive settings by the school administration. According to Hegarty, and Pocklington, with Lucas, (1988). cited in Fekede (2005), the head must be an all rounded person in looking the problems and needs of children. This implies that, if an integration program for students with physical disabilities is to be successful, the head of the school must have a positive 
attitude towards integration.

Similarly, as indicated in item 15 of table 5, almost all 49 $(49 \%)$ of these students shown their disagreement again concerning the professional support provided for teachers, principals and the SWD aiming at creating initiative and significant inclusion in PE classes in the sample schools. The mean value of this item (1.08) is also below the average (3).
Thus the school society particularly teachers and principals did not offered sufficient professional supports from the experts who might be better than them in terms of skills and knowledge. Anderson (1992) as cited in Bizuneh (2008) further stated that absence of professional supports provided in various form may affect teachers' performances which could be crucial for provision of quality education.

Table 7. Psycho-social Challenges in Inclusive PE as Perceived by SWD.

\begin{tabular}{|c|c|c|c|c|c|c|c|}
\hline \multirow{3}{*}{ No } & \multirow{3}{*}{ Item } & \multicolumn{6}{|c|}{ Rating scales } \\
\hline & & & $\mathbf{A}$ & UD & DA & \multirow{2}{*}{$\sum$} & \multirow{2}{*}{$\mathbf{M}$} \\
\hline & & & 5 & 3 & 1 & & \\
\hline \multirow{2}{*}{28.} & I have several psychological problems because of my disability since I can't & $f$ & 43 & - & 7 & 50 & \multirow{2}{*}{4.5} \\
\hline & participate in PE classes equally with others & $\%$ & 86 & & 14 & 100 & \\
\hline \multirow{2}{*}{29.} & Isolation from PE practical classes decrease the social interaction skill of students & $f$ & 40 & 1 & 9 & 50 & \multirow{2}{*}{4.24} \\
\hline & with disabilities & $\%$ & 80 & 2 & 18 & 100 & \\
\hline
\end{tabular}

As the data obtained from the sample schools in table 6 above, the student respondents emphasize that there exclusion from PE practical activities affect their psychosocial conditions. For instance, for item 29 which elaborates the psychological problems faced by the SWD due to their inability to be involved in PE programs, majority of students
$40(80 \%)$ of the total respondents indicates that they have so much psychological problem because of their society perception towards disabled students. In addition the mean values of the items 4.5 and 4.24 confirmed that the problems are very strong.

Table 8. Effort made by Teachers, Woreda, and Zone Education Bureau Experts to Effectively Include Students with Physical Disabilities in PE Practical Classes.

\begin{tabular}{|c|c|c|c|c|c|c|c|c|c|}
\hline \multirow{3}{*}{ No } & \multirow{3}{*}{ Item } & \multicolumn{8}{|c|}{ Responses } \\
\hline & & \multicolumn{2}{|l|}{ Yes } & \multicolumn{2}{|l|}{ No } & \multicolumn{2}{|c|}{ Some times } & \multicolumn{2}{|c|}{ Total } \\
\hline & & No & $\%$ & No & $\%$ & No & $\%$ & No & $\%$ \\
\hline 6 & $\begin{array}{l}\text { Have you tried to modify practical activities of PE in order to meet the special } \\
\text { needs of SWD? }\end{array}$ & 1 & 11.1 & 6 & 66.7 & 2 & 22.2 & 9 & 100 \\
\hline 7 & $\begin{array}{l}\text { Do you evaluate students with disabilities in the practical session of PE with } \\
\text { other students? }\end{array}$ & 1 & 11.1 & 6 & 66.7 & 2 & 22.2 & 9 & 100 \\
\hline 8 & $\begin{array}{l}\text { Is there professional support from educational experts of the zone and woreda for } \\
\text { teachers and principals to promote the inclusion of SWD in PE practical classes? }\end{array}$ & & & 8 & 88.9 & 1 & 11.1 & 9 & 100 \\
\hline
\end{tabular}

Concerning the modification of instruction made by teachers according to the needs and disabilities of the students, $6(66.7 \%)$ and $2(22.2 \%)$ of the respondents replied 'no' and 'sometimes' respectively, while 1(11.1\%) of them responded 'yes'. This implies that the inefficient competence of teachers for the improvement of inclusion of SWD in PE. However, Salend (1994) advocated that, while a variety of techniques exist for adapting the learning environment to promote the optimal performance of mainstreamed students, the selection of an appropriate modification will depend on several factors, including the students' learning needs and the teachers' instructional styles.

Regarding to item 7 of Table 7 , that reflects whether students with disabilities involved in the practical tests of PE or not, majority of the subject teachers $6(66.7 \%)$ and $2(22.2 \%)$ replied that 'no' and 'sometimes' respectively. One can simply understand from the data that students with orthopedic, visual and hearing impairments were rejected from practical tests of PE. This is due to their rejection primarily from the regular practical classes. In the previous analysis part, student respondents confirmed the same thing that they are almost out of the inclusive PE practical classes as well as the practical assessment processes.

Furthermore, they underlined that, being out of this session of education decrease their result and they cannot compete for rank with others. The actual observation result of the researcher showed that students with disabilities were almost out of PE practical classes and tests. As Tirusew (2005) says, inclusive education requires a flexible educational system including flexible curriculum, facilities, or other aspects of the setting. Moreover, Skjorten (2004) suggested that, for successful inclusive education, reorientation related to assessment, teaching methods and classroom management (including adjustment of the environment) must be carefully weighted before implementation.

In the case of professional support provided from the zone and woreda educational experts to principals and teachers in order to create successful inclusion of SWD in PE practical classes, majority $8(88.9 \%)$ of the respondent teachers pointed out that the absence of professional support from zone and woreda educational bureau.

Further, the interview conducted with principals of the sample schools confirmed that support and encouragement given by experts is not specifically directed to inclusion in PE. As to them, the support provided from those officials was toward the general teaching-learning process. Hence, specific consideration was not given to inclusive education. Supporting this idea, one expert from woreda education 
bureau explained as follows:

... Even though currently the government tries to change the situation of inclusive education by giving workshops to create awareness among some stakeholders, still there is no more change as required, because the awareness creation given was not adequate and continuous.

\section{Conclusion}

Physical education is the integral part of the total educational activities which enhances and integrates the mental, physical, social, and psychological aspects of an individual's life through directed and selected physical activities. Therefore, one has to understand that physical education plays a great role in the society, especially for SWD if efficiently and effectively practiced.

As seen from the general trend, although most educators consider inclusive education to be ethically, morally, and pedagogically sound for students with disabilities, a number of obstacles have interfered with its wide spread implementation. As a result, SWD denied access to inclusive education. Similarly, significant number of students with orthopedic, visual, and hearing impairments lack access to participate in physical education practical exercises in the school.

Therefore, the focus of this study was to identify the existing practice of SWD in PE practical classes along with challenges and opportunities in the process. In addition, it is aimed at forwarding possible solutions to improve the involvement of students with orthopedic, visual, and hearing impairments in PE practical activities.

\section{Recommendations}

Based on the findings and conclusion of the study, the following recommendations were forwarded to be taken by the government, schools, and teachers.

\subsection{Measures to Be Taken by the Government}

a. There must be clearly stated guidelines to provide inclusive education to children with different types of disability. Legislation, educational policy, and teacher training programs also need to be progressively updated to realize inclusive education as an educational modality;

b. The ministry of education should modify the teacher training curriculum so as to reflect the necessary competencies needed by teachers who are to take a leadership role in order to facilitate the development of inclusive schooling. Hence, the government has to provide long-term and short-term trainings at regional and central level for teachers who are teaching in inclusive school;

c. Awareness creation system should be designed and provided to regional, zonal and woreda educational officers and to school principals in order to activate stakeholders for the success of inclusive education, and

d. The government has to allocate budget specifically for fulfilling the materials needed by students with disabilities in collaboration with domestic and international non-governmental organizations.

\subsection{Measures to Be Taken at School Level}

a. The school should create awareness among the school community (teachers, SWD, SWOD etc.) and parents. This would help the school community to develop positive attitude toward SWD and inclusive education;

b. The school has to support and encourage teachers to produce and utilize relevant instructional materials which are locally made to promote the teachinglearning process in field activities;

\subsection{Measures to Be Taken by Teachers}

a. Teachers have to be well aware of students with orthopedic, visual and hearing impairments so that they can have a better understanding and positive attitude to promote inclusive PE;

b. Teachers could encounter practical problems, while teaching in inclusive classes. Thus, teachers should be innovative, flexible, creative, ready to learn from the learners and capable of initiating active learning in inclusive PE setting;

c. Teachers should work out the necessary modification and adaptation of educational materials, methodology, facilities, and equipment in order to address specific educational needs of students with orthopedic, visual, and hearing impairments in physical education,

d. Teachers need to revision PE text books so as to incorporate more suitable activities and methodologies that promote communication and participation.

\section{References}

[1] Auxter, D., Pyfer, J., \& Huetting, C. (1997).Adapted Physical Education and Recreation. London: Mosby.

[2] Bizuneh Kebu (2008). Status of Special Needs Education: The Case of Arsi Zone Primary Schools. (Unpublished).

[3] Dauer, V. P. \&Pangrazi, R. P. (1979). Dynamic Physical Education for Elementary School Children. Minneapolis: Burgres Publishing Company.

[4] Degefa Abdi (2001). The Attitudes of Students with Visual Impairments towards Physical Education: The Case of Sebeta and Boko Schools for the Blinds in West Shewa Zone of Oromia Regional State. (Unpublished).

[5] Hegarty, and Pocklington, with Lucas, (1988).Education pupils with Special Needs in the Ordinary School $4^{\text {th }}$ ed. Great Britain, NFER-NELSON Publishing Company.

[6] Salend, S. J. (1994). Effective Mainstreaming: Creating Inclusive Classroom. ( $2^{\text {nd }}$ ed). Englewood Cliffs, N. J Merrill/Prentice Hall.

[7] Skjorten, M. D. (2004). Towards Inclusion and Enrichment Article in Johnson, Beritand Skojorten, Miriam D. (ed.), Special Needs Education: Introduction, Oslo, Unpublished. 
[8] Tirussew, T. (2000). Human Disabilities: Developmental, Educational and Psychological Implications. Addis Ababa: AAU Press.

[9] Tirussew, T. (2005). Disabilities in Ethiopia: Issue, Insights and Implementation: Addis Ababa. AAU Press.
[10] West, R. (1997). Examination in Central and Eastern Europe Newsletter of the Association of Teachers of English of the Czech Republic. 